\title{
Rapid functional diversification in the structurally conserved ELAV family of neuronal RNA binding proteins
} Marie-Laure Samson

\author{
Address: Laboratoire Signalisation, Développement et Cancer, UMR8080 Développement et Evolution, CNRS and Université Paris Sud, Bâtiment \\ 442 bis, 91405, Orsay Cedex, France
}

Email: Marie-Laure Samson - Marie-Laure.Samson@u-psud.fr

Published: 20 August 2008

BMC Genomics 2008, 9:392 doi:10.1186/147|-2164-9-392

This article is available from: http://www.biomedcentral.com//47/-2/64/9/392

(c) 2008 Samson; licensee BioMed Central Ltd.

This is an Open Access article distributed under the terms of the Creative Commons Attribution License (http://creativecommons.org/licenses/by/2.0), which permits unrestricted use, distribution, and reproduction in any medium, provided the original work is properly cited.
Received: 30 january 2008

Accepted: 20 August 2008

\begin{abstract}
Background: The Drosophila gene embryonic lethal abnormal visual system (elav) is the prototype of a gene family present in all metazoans. Its members encode structurally conserved neuronal proteins with three RNA Recognition Motifs (RRM) but they paradoxically act at diverse levels of post-transcriptional regulation. In an attempt to understand the history of this family, we searched for orthologs in eleven completely sequenced genomes, including those of humans, D. melanogaster and $C$. elegans, for which cDNAs are available.
\end{abstract}

Results: We analyzed 23 orthologs/paralogs of elav, and found evidence of gain/loss of gene copy number. For one set of genes, including elav itself, the coding sequences are free of introns and their products most resemble ELAV. The remaining genes show remarkable conservation of their exon organization, and their products most resemble FNE and RBP9, proteins encoded by the two elav paralogs of Drosophila. Remarkably, three of the conserved exon junctions are both close to structural elements, involved respectively in protein-RNA interactions and in the regulation of subcellular localization, and in the vicinity of diverse sequence variations.

Conclusion: The data indicate that the essential elav gene of Drosophila is newly emerged, restricted to dipterans and of retrotransposed origin. We propose that the conserved exon junctions constitute potential sites for sequence/function modifications, and that RRM binding proteins, whose function relies upon plastic RNA-protein interactions, may have played an important role in brain evolution.

\section{Background}

The elav (embryonic lethal abnormal visual system) gene of $D$. melanogaster was the the first identified member of a family of neuronal RNA binding proteins that is conserved in metazoans $[1,2]$. The proteins in this family contain three RNA Recognition Motifs (RRM), with a hinge region separating the second and third RRMs and an optional nonconserved N-terminal region. The hinge includes signals essential for nuclear export and subcellular localization [3].
RRM are common protein domains found in all life kingdoms. In humans, there are 497 genes encoding RRM containing proteins, which represent $2 \%$ of the human gene products. Proteins containing one or several of these domains are capable of interacting in a sequence specific manner with single stranded RNA molecules and of directing the assembly of multiprotein complexes [4,5]. In spite of the remarkable sequence conservation of the RRM domains, RRM-containing proteins perform numerous functions, intervening at all the possible steps of RNA 
metabolism. The RRM domain is composed of about 90 amino acids and contains a conserved octapeptide termed RNP-1 (ribonucleoprotein motif) and a conserved hexapeptide termed RNP-2. Structural studies indicate that four antiparallel beta-sheets form the RNA interaction surface, with RNP-1 and RNP-2 on the two inner sheets (beta 1 and beta 3 ). In RNA-RRM complexes, nucleotides establish contacts with residues in the RNPs, with regions in the RRM beyond the RNP domains also involved in RNA recognition. The plasticity of RRMs in their sequence-specific recognition of topologically diverse RNA is likely to be correlated with their presence in a variety of proteins involved in the diverse steps of post-transcriptional regulation.

There are three elav-related genes in D. melanogaster. The elav gene encodes a nuclear product present in all neurons throughout development and is required for the differentiation of postmitotic neurons and their maintenance [1]. The rbp9 (RNA binding protein 9) product is present in neuronal nuclei starting at the third larval instar and also in the cytoplasm of cystocytes during oogenesis. Although neuronal expression is predominant, rbp9 mutations reveal a role in cystocyte proliferation and differentiation, but no neuronal defects have been reported $[6,7]$. The expression of fne (found in neurons) resembles elav's, but with a slightly delayed onset. FNE is cytoplasmic, but the elav and fne genes interact, suggesting protein shuttling $[8,9]$. The products of elav family members are essentially present in the nervous system, in all of the neurons in the case of elav itself, but more generally in subsets of neurons and/or neuroblasts and glial cells. Expression has also been detected in other tissues, in particular in testes and ovaries, or found to be ubiquitous (for instance [10]). Diverse molecular functions in the control of RNA half life, nuclear export, RNA 3' end formation, alternative RNA processing, polyadenylation and translation have been proposed for these proteins [9,11-17]. Multiple functions, both cytoplasmic and nuclear have been demonstrated for HuR, an ubiquitously expressed member of the human family $[11,16,17]$.

The evolutionary relationship between members of the family are complex. For instance, the four human proteins share $74-91 \%$ identity, while the three Drosophila proteins share only $59-68 \%$ identity. The goal of the work reported here was to investigate these relationships. We found that the elav family has an eventful evolutionary history, somewhat masked by the high level of amino acid conservation of the gene products, but revealed by analysis of the gene structure of the different family members (11 species, 23 proteins). We attribute the rapid functional evolution of the family members, as opposed to the high level of sequence conservation, to the plasticity of the
RRM domains, where small changes in critical positions have the potential to modify interactions with RNA.

\section{Results}

The paralogs fne and rbp9 share a conserved organization of their coding regions but elav, the third family member, is distinct

All three Drosophila paralogs elav, rbp9 and fne are essentially expressed in neurons. elav null mutants are embryonic lethal, while the rbp9 null mutation is viable, but surprisingly confers a female sterility phenotype. fne null mutants, although not fully characterized, are also viable (Zanini and Samson, in preparation). In order to understand the evolutionary mechanisms responsible for the generation of these paralogs, we examined their gene structure. Although their organizations are apparently quite distinct, we found remarkable conservation in the correspondance between exons and specific protein regions in $r b p 9$ and fne (Fig. 1A). There are two differences (1) the presence of new mini-exons respectively specific for each of the two genes and (2) the use of a single exon

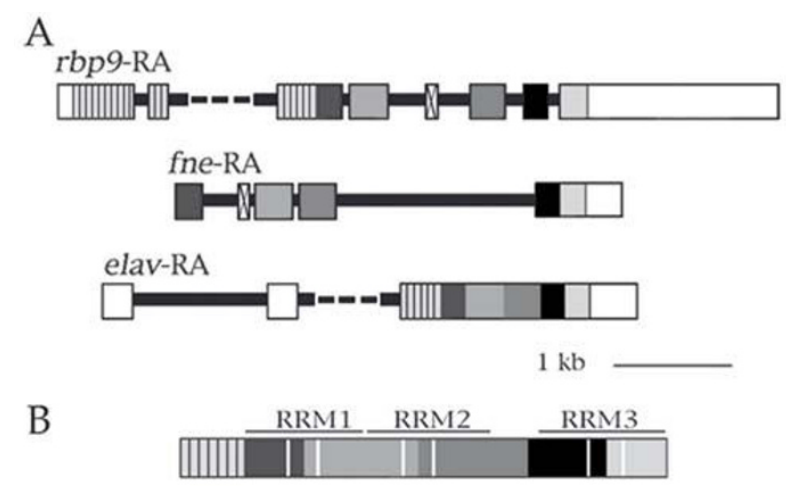

\section{Figure I}

Correspondance between exons and protein regions in the elav family of D. melanogaster. A: RNA structures. RNA nomenclature as in FlyBase, with details in the Methods. Boxes represent exons. The black horizontal lines are introns, with dashes respectively replacing the $5.8 \mathrm{~kb}$ long intron in the rbp9-RA transcript and the $2.2 \mathrm{~kb}$ long intron in the elav-RA transcript. White: non coding, Vertical stripes: non-conserved, Crossed: gene-specific mini-exons, respectively a 15 nucleotide long region present in alternative forms of rbp9 and a 45 nucleotide long region present in fne. All others are color coded based upon sequence similarity and according to exon-exon boundaries. B: Schematic representation of the ELAV family protein products. The color coding corresponds to that used for the RNA representation. The regions encoded by gene specific sequences have been omitted. RRM: RNA Recogntion Motif. The pairs of white vertical bars represent conserved motifs (RNP-I and RNP-2) diagnostic of RRMs. 
in fne but two in rbp9 to encode the third RRM. Strikingly, this organization is totally different in the elav gene, whose complete ORF, except for the A of the ATG initiation codon, is encoded by a single exon.

\section{Conserved exon junctions are present in most elav orthologs}

We took advantage of the recent sequencing of complete genomes [18-22] to survey the gene family in 11 species by (1) identifying all the family members and (2) comparing the organization of the ORF in exons. In humans, $D$. melanogaster and C. elegans, we extracted from the databases protein sequences deduced from cDNA analyses, and aligned genomic DNA with cDNA to determine the exon-intron structure. In other cases we used the predicted protein sequences, either published or computed for our purpose, as detailed in the Methods. We examined species from the chordata ( 1 species), arthropoda (9 species) and nematoda (1 species), for a total of 23 genes (Fig. 2).

First, we found that the size of elav families varies (one to four members) among the 11 species that we studied, with no clear relationship between family size and brain/ animal complexity (Fig. 2). For instance, dipterans possess three elav genes, while the hymenopteran Apis mellifora, with ten times as many neurons as Drosophila, possesses only one gene. Levels of identity between the proteins encoded by the 23 genes are high, with the lowest score $(47 \%)$ obtained in the comparison of D. melanogaster ELAV with the unique C. elegans protein. Between humans and Drosophila, there is $54-64 \%$ amino acid identity in the ELAV-related proteins, 38\% identity for the arginase proteins (ubiquitous metabolic enzymes, see below) and 33\% identity for the engrailed proteins (conserved transcription factors, not shown). The levels of ELAV-related protein identity are thus remarkable. The crystal structure of the first two RRM of human HuD associated with cfos RNA, identifies 12 amino acids whose side chain is making direct RNA contacts [23]. These residues are conserved in all 23 ELAV-like proteins that we examined, except for the arginine in RNP1 of the second RRM, which appears to be specific to the human proteins and to one of the B. mori ELAV-like, Bm-2. In the other species there is a conserved substitution by a lysine.

Second, we found remarkable conservation of exon structure. From vertebrates to invertebrates, we identified eight exon junctions in the RRMs/hinge region (Fig. 3). We named them J1 to J8, from the most upstream to the most downstream. All are present in several phyla, except for J1 and J4 which are specific for FNE and RBP9 from Drosophila and are implicated in the generation of miniexons in the sequence coding (alternative forms of) these proteins (Fig. 1 \&3). Overall, the J2 junctions (respectively J3, J5 and J8, Fig. 2 \&3) are unambiguously homologous since (1) the level of protein sequence conservation is such that the amino acid positions where the junctions intervene are clearly aligned and conserved (Fig. 3) and (2) nucleotide sequence analysis shows that at a given exon junction, the splice is at the same position in the codons: specifically between the first and the second bases of the spliced codons (for J2 and J5, as well as for the species-specific J1 and J4) or exactly between codons (J3 and J8). There are two exceptions to this strict conservation. First, J5 is interrupted in rbp9 of D. melanogaster by the intronic insertion of an alternative mini-exon, without alteration of the J5 5' or 3' splice sites. Second, in fne, J2 is split by the intronic insertion of a mini-exon, the J2 donor splice site is additionally shifted downstream while the J2 acceptor splice site is maintained (Fig. 3). Interestingly, the junctions $\mathrm{J} 2$ and $\mathrm{J} 5$ occupy the same position relative to RNP-1 in RRM1 and RRM2.

The junctions $\mathrm{J} 6$ and $\mathrm{J} 7$ map in a moderately conserved coding region, essential for nuclear export and proper subcellular localization (Reviewed in [2]), including only a conserved hexamer (R-SP----). Both J6 and J7 split the spliced codons between the second and the third bases. In this region, three types of events affecting the splicing seem to have occured independently: 1) the introduction of a mini-exon (in humans), that can be alternatively spliced (HuB), (2) the shift of the 5' splice site (example: $N$. vitripennis vs T. castaneum) (3) the shift of the 3 ' splice (example: the T. castaneum vs $A e-2$ genes or the alternative human forms HuD-366 and HuD-380). Noticeably, the regions close respectively to J1/J2, J4/J5 and J6/J7 as well as the entire hinge region between RRM2 and RRM3 appear more variable than the rest of the protein.

\section{Intronless elav-like genes are present in Diptera and Lepidoptera}

Interestingly, for six of the analyzed genes $(A g-1, A e-1, C p$ 1, elav in Diptera, and $B m-1, B m-2$ in Lepidoptera), the entire conserved region of the protein is encoded by a single exon. Based upon both their gene structure and the level of protein sequence identity, the dipteran intronless genes constitute a homogeneous elav-type group. In contrast, although intronless like elav, the B. mori genes encode proteins more similar to FNE/RBP9 than to ELAV. This observation suggests that distinct evolutionary forces shaped the B. mori genes and the dipteran elav-like intronless-genes, respectively. To evaluate this hypothesis, we performed a phylogenetic analysis of the 27 ELAV orthologs/paralogs, using the UPGMA algorithm, with bootstrap analysis (Fig. 4). This analysis shows with high confidence (bootstrap values greater or equal to $99 \%$ ) that in dipterans, the proteins encoded by the intronless genes (Ag-1, Ae-1, Cp-1, elav) cluster together, while the two $B$. mori genes products cluster with the FNE/RBP9 sequences Similar results were obtained when performing sequence 


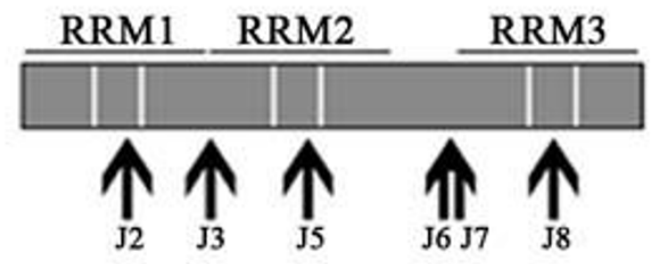

$\%$ identity with ELAV FNE RBP9

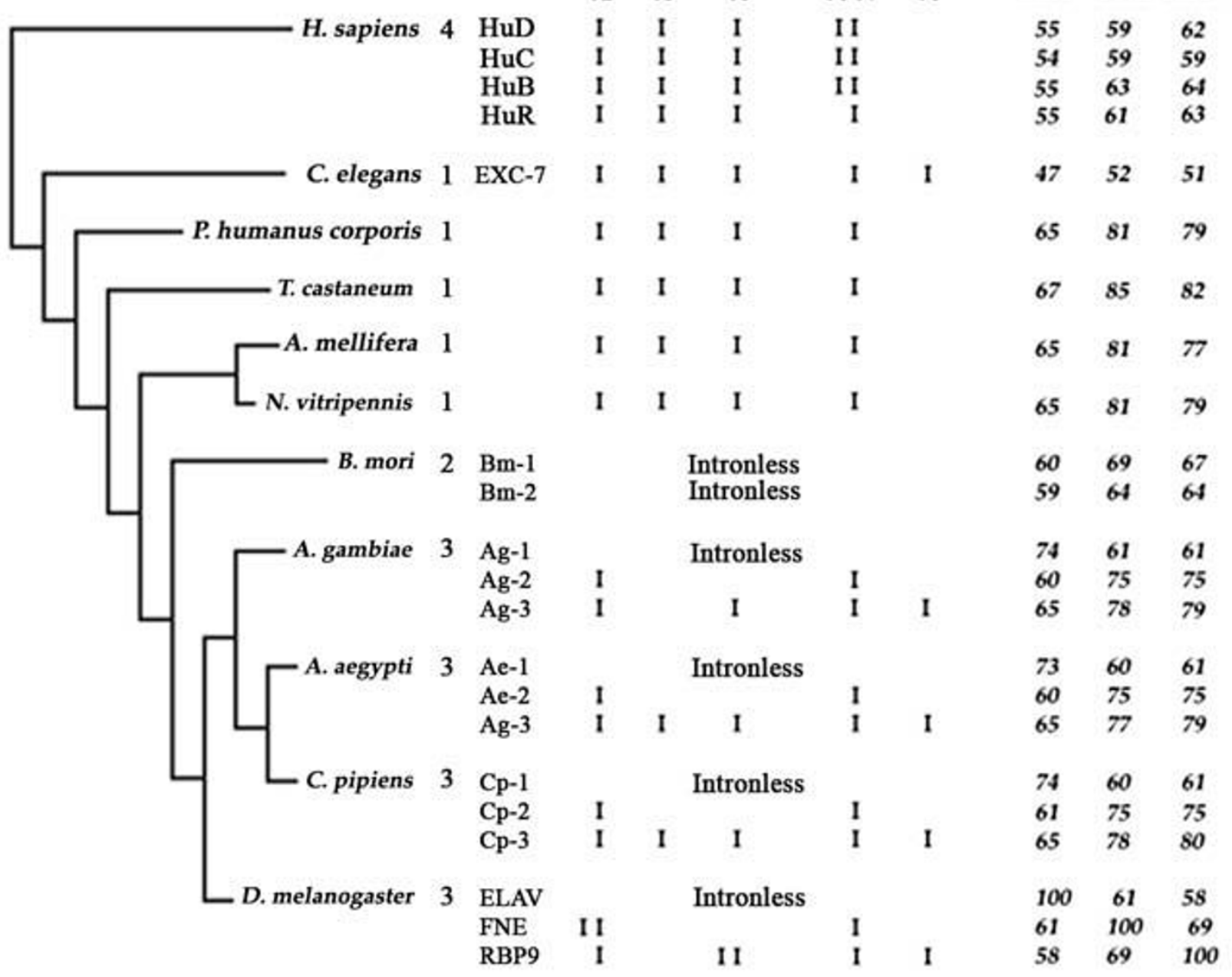

Figure 2

Exon organisation of the elav-related genes in I I metazoans. The analyzed species are listed on the left, with classical phylogenetic relationships represented. The number of elav-like genes is listed next to the species names. Percentages of identity between their protein products and the D. melanogaster proteins ELAV, FNE and RBP9 are listed on the right side of the figure. At the top, a typical ELAV-like protein is represented, with its three RRMs and the hinge region between RRM2 and 3. The vertical arrows below point at protein regions that are, depending upon each of the 23 analyzed proteins, either encoded by exon-junctions $(\mathrm{x}, \mathrm{x}=\mathrm{I}$ to 8 , see text) or by an internal exon sequence. The presence of the junction-encoded region is indicated by a vertical bar for each protein.

alignments using the neighbor joining method (not shown).

Because the D. melanogaster elav gene is nested in the third intron of the arginase gene [24], we probed the gene envi- ronment of the intronless elav orthologs that we report here. We found that the nested elav/arg gene organization is unique to Drosophila, specifically D. melanogaster and 11 additional Drosophila species whose genomes have recently been sequenced [25] (Fig. 5). In the 10 other non- 

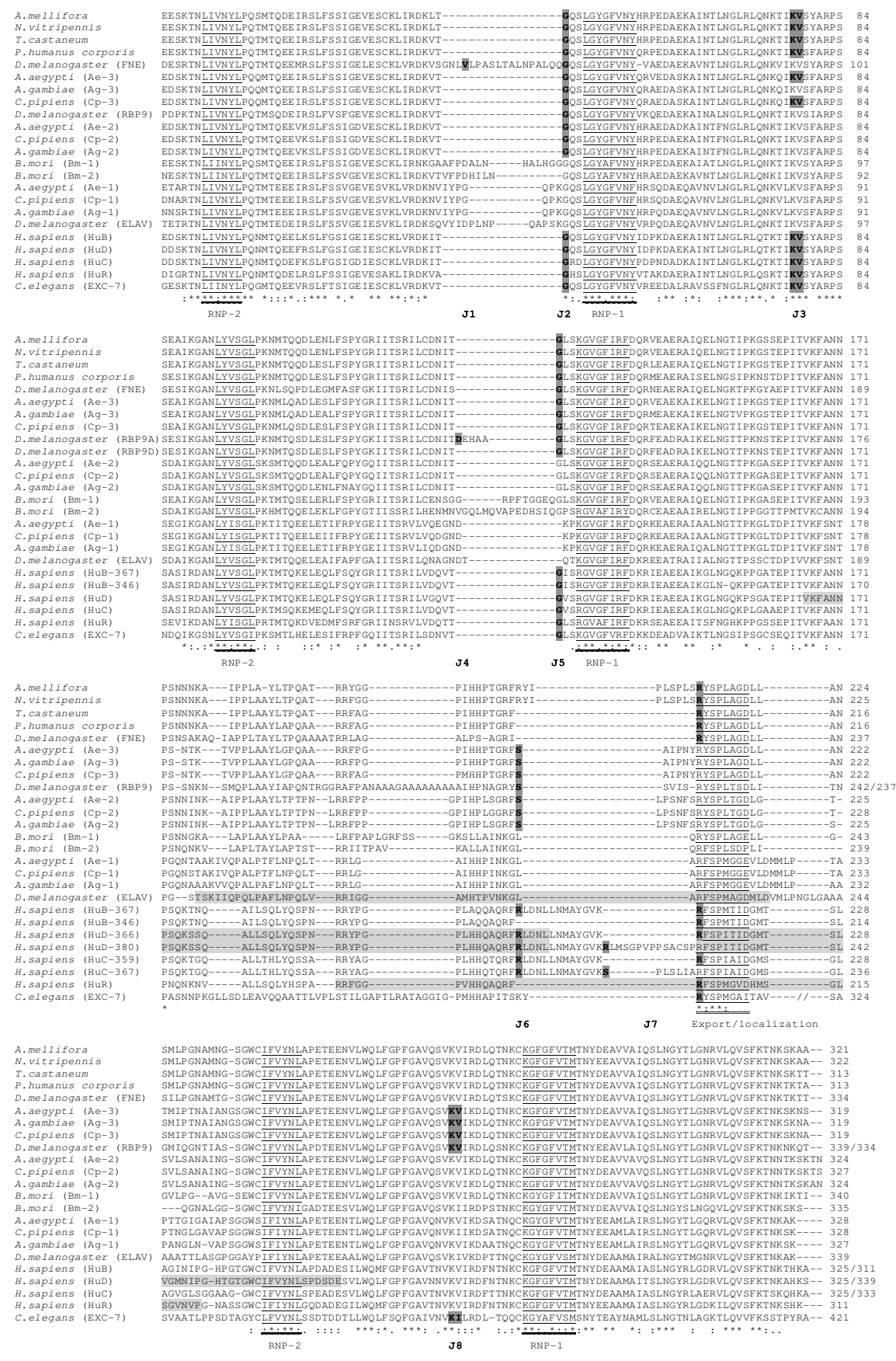

\section{Figure 3}

Protein sequence comparison among 27 ELAV-like proteins forms. Alternative protein forms are included, specifically for Drosophila RBP9 (A and D) and three of the human proteins ( HuB, HuC and HuD, where HuX-n refers to the $n$ amino acid long form of the HuX protein). "*" indicate that amino acids are identical in all 27 sequences, ":" and "." respectively indicate conserved and semi-conserved substitutions. The octamer RNP-I and the hexamer RNP-2, diagnostic of RRMs, are underlined. Also underlined is a conserved octamer present in the region that is crucial for nuclear export and localization. The regions in light grey boxes have been mapped as necessary for these processes in D. melanogaster ELAV, human HuR and human HuD. We identified eight exon junctions labelled Jl to $\mathrm{J} 8$ (see text). Bold characters and dark grey boxes are used to identify amino acids encoded by exon junctions. When the splicing connects intact codons, two amino acids are bold (J3 and J8). The symbol//replaces 85 non-conserved amino acids in the $C$. elegans sequence. 


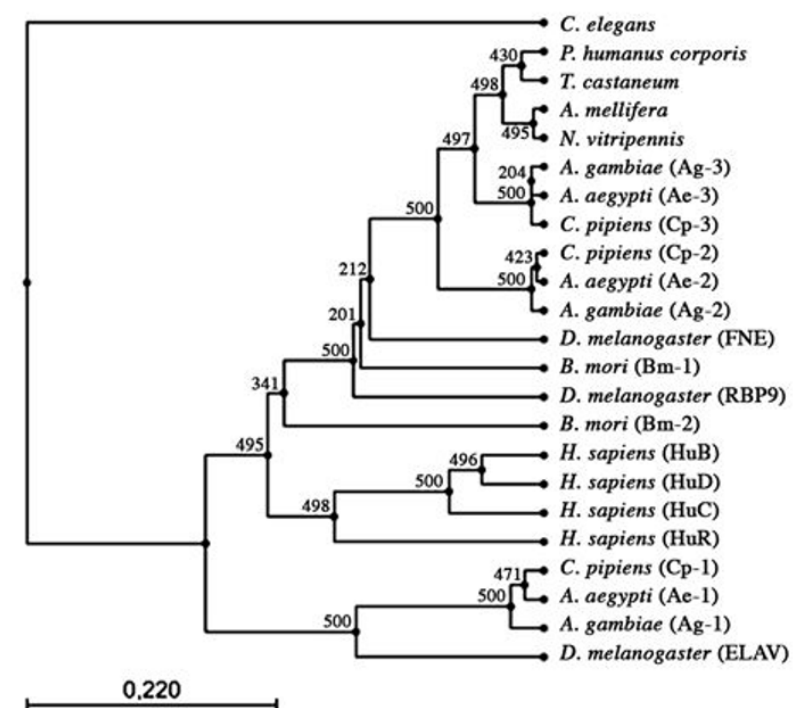

Figure 4

Phylogenetic tree of 27 ELAV-like proteins. Sequences were aligned and bootstrapped 500 times. Numbers near the branches are the bootstrap values, and the scale indicates the number of substitutions per site.

Drosophila species examined here, there is no close linkage between the arginase gene(s) and the elav gene family members. In particular, the mosquitos, similar to D. melanogaster, each have three elav-like genes, including one intronless version, but unlike D. melanogaster they have an intronless $a r g$, which obviously rules out the possibility of a nested gene. In $B$. mori, although the two intronless $\mathrm{Bm}$ 1 and $B m-2$ genes map at loci distinct from the arg locus, an intron putatively homologous to the third intron of the D. melanogaster arginase gene is present (Fig. 5).

\section{Discussion}

The D. melanogaster gene elav is specific to the dipteran phylum and results from retrotransposition

The elav gene from Drosophila was the first identified member of this family, is considered as its prototype [1], and most of the subsequently discovered orthologs are named after it. However, the present analysis highlights unique characteristics of this gene that suggest it is of recent evolutionary origin, after the separation of dipterans and lepidopterans. Aside from elav, only the dipteran genes $A e-1, A g-1$ and $C p-1$ encode proteins that are more similar to ELAV than to FNE and RBP9. In addition to the intronless elav-likes, dipteran genomes carry two genes encoding proteins of the type FNE/RBP9, also found in the seven other genomes analyzed. Thus elav, Ae-1, Ag-1 and $C p-1$ represent a newly evolved gene form specific to dipterans.

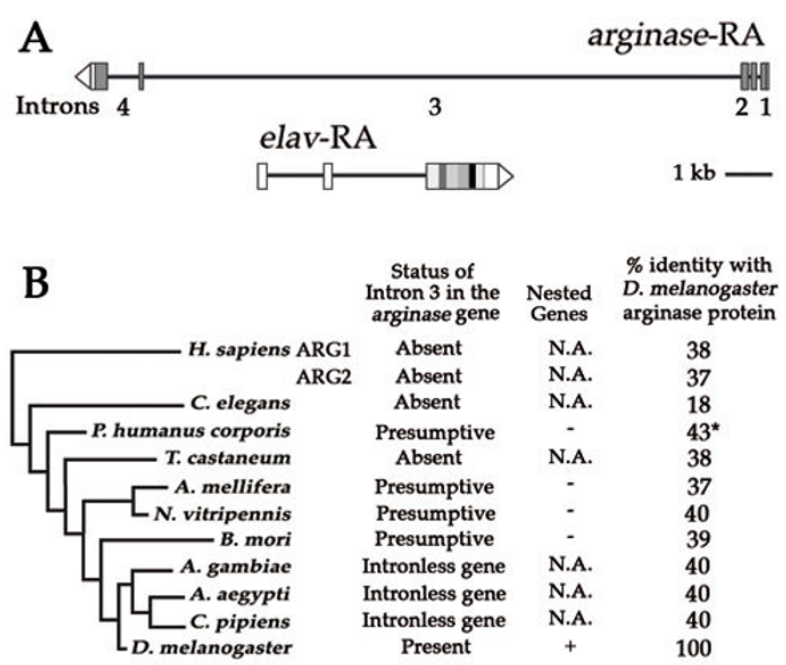

Figure 5

A unique nested gene arrangement for the elav and arginase genes in $D$. melanogaster. A: The elav gene is nested inside the third intron of the arginase gene. Complementary strands are transcribed to generate the elav and arg RNAs with inverse polarities [28]. B: Examination of the relative arg-elav arrangement in II metazoans. There are two arginase genes in humans, only one in the other examined species. Column I documents the status of the arginase third intron. Column 2 specifies the nested (+) or independent (-) arrangement of the arginase/elav genes. N.A.: Not applicable. The third column indicates the percentage of amino-acid sequence identity of $D$. melanogaster compared with other species. *: $\mathrm{N}$-terminally truncated arginase sequence for $P$. humanus corporis. See Additional file 3 for arginase alignments.

In addition, the elav gene structure is suggestive of retrotransposition, a process considered significant in the evolution of genomes, including Drosophila [26]. The genes $A e-1, A g-1$ and $C p-1$ from mosquitoes share with elav not only a higer level of similarity between their products, but also the property of having their ORF in a single exon. The absence of introns (restricted to dipterans and B. mori in this gene family) is atypical: we identified conserved exon junctions that are a landmark present in most of the elavrelated genes. Furthermore, the elav gene of Drosophila is nested in the arginase gene. In humans, retrotransposition is an important contributor to the generation of nested genes [27]. We thus propose that elav originated from a recent retrotransposition event. It is possible that the same retrotransposition is at the origin of both the lepidopteran intronless fne/rbp9-like genes and the dipteran elav-like genes. A duplication of the retrotransposed gene in the ancestor to $B$. mori and different fates for the ancestral gene copies in the two groups would bring about the present situation. Alternatively, we do not exclude that 
independent retrotranspositions happened in lepidopteran and dipteran ancestral lineages.

Interestingly, the nested arg/elav arrangement found in $D$. melanogaster is not conserved in the mosquitoes, where the host gene (arginase) became intronless. This parallels the nested arrangement of the intronless sina gene in an intron of the Rh4 gene, as found in mosquitoes and nine species of the Drosophila genus. The remaining three species of the genus have an intronless Rh4, with a loss of the ancestral $R h 4$ copy where sina was originally embedded [28]. These situations show the lability of nested gene arrangements.

\section{elav: the genesis of a new function}

It was unexpected to find that the copy number of elav family members varied from species to species. Given the maintenance of this gene family in all metazoans, we assume that there is a function for at least one, if not all, of the genes in each species. Mutants have been reported in only three species. The knockout of neuronal $\mathrm{HuD}$ in mice causes motor and sensory defects [29]. It is not excluded that the mild phenotype of this mutant is the consequence of gene redundancy. In C. elegans, cholinergic synaptic transmission is altered in mutants of the single elav ortholog EXC-7, which is expressed in a subset of neurons and other non-neuronal cells [30]. In both cases, viability and apparent morphology are normal. In Drosophila melanogaster, the vital gene elav is required in all neurons [1], whereas $r b p 9$ is essential for female fertility [7] but does not affect viability. We recently generated null mutations of the fne gene (Zanini and Samson, in preparation), whose preliminary analysis indicates that they are viable in adults and lead to no apparent morphological defects. Aside from elav itself, characterized mutations of the elav gene family are viable, suggesting a nonvital function of the ancestral gene.

Considering that elav appears to be a new member of the family, its vital function is quite striking. This situation is reminescent of that of Sex-lethal (Sxl), a gene fundamental to sex determination in Drosophila, but which does not act as a sex determining factor in non-Drosophilids. The Drosophilid genomes indeed contain two $S x l$ paralogs (79\% identity in D. melanogaster), while non-Drosophilids have one. It has been proposed that there was a duplication of the ancestral gene in Drosophilids and acquisition of a new function by one of the copies [31]. We believe that a retrotransposition of the elav/fne/rbp9 ancestor gene at the time of the separation of dipterans/ lepidopterans led to a gene duplication and the evolution of a new function for elav.

\section{Conserved RNA binding proteins: a reservoir for accelerated functional evolution}

We have pointed out that the ELAV-like proteins, including ELAV itself, have maintained a high level of sequence conservation between species, higher than that of engrailed, a conserved transcription factor with a homeodomain, or that of arginase, a ubiquitous metabolic enzyme that arose before the divergence of procaryotes and eucaryotes. This is intriguing in light of the extensively documented diversity of the properties of individual members of the family. First, although there is expression in the nervous system of at least one of the elav family members in every investigated metazoan (mammals, fishes, amphibians, birds, amphioxus, C. elegans, $D$. melanogaster), expression is also detected in other tissues and is even sometimes ubiquitous [2]. Second, the functions of these proteins are multiple, whether at the cellular level, where they include cell differentiation/survival $[1,6,29,32]$ and cell proliferation/control of the cell cycle $[7,33]$ or at the biological level, with impacts on motor/ sensory activity, memory, fertility or viability $[1,6,29,34]$. Finally, the apparent subcellular localization of these proteins is diverse (nuclear, subnuclear, cytoplasmic or both), in agreement with diverse molecular functions $[2,3]$.

The data thus reveal a diversification of the functions and of the specificity of expression of ELAV family members and implies a diversification of the interactions with other macromolecules, most evidently the RNAs whose metabolism is regulated by the RRM containing proteins. The DNA duplications and retrotranspositions that occured in the elav gene families constitute a starting point for the diversification of gene function. Changes in cell or tissue specificity of expression are often linked to modifications of non-translated regulatory regions. However, changes affecting the sub-cellular localization, known to be dependent upon the hinge region between RRM2 and RRM3, or changes in the interactions with proteins or RNA must depend upon the protein product of the elavlike genes.

Sequence alignments of the ELAV-like proteins shows that they are overall very conserved. But we were puzzeld by the fact some of the conserved exon junctions (J1/J2, J4/J5 and J6/J7) are adjacent to sequences that are among the most variable of the proteins. They include short insertions of amino acids, (alternative) exon addition and amino acid variations. The intron sequence indeed provides a potential source of sequence variability: it is conceivable that intron extremities become integrated into coding sequences by shifting of the exon boundaries. Alternatively, the intron can serve as the site of insertion of a new exon. An additional surprising point was the fact that these variable micro regions are almost directly upstream of important conserved motifs, specifically 
RNP-1 (in RRM1 and RRM2) and the octapeptide in the region essential for nuclear export and subcellular localization. The modification of residues outside of the RNP has the potential to alter the interactions between the RRM and an RNA [5]. Additionally, alterations of the region responsible for nuclear export/cellular localization modify this function (reviewed in [2]). We thus propose that the maintenance of the exon junctions is vital to the evolution of the ELAV family, in particular the generation of new functions. As a consequence, one would predict that RRM1, RRM2 and the hinge region have prominent roles in functional specificity. It may be significant in this respect that RRM3 replacements in ELAV by RRM3 from RBP9 or HUD are fully functional, while RRM1 or RRM2 replacements by corresponding RRMs from RBP9 or SXL are largely non-functional [35].

More generally, it seems that RRM-containing proteins could serve as favorable targets for the rapid evolution of gene functions. Because of the structural versatility of the RRM domain, it can be adapted for sequence specific recognition of many different nucleic acid structures and different protein partners [5]. The SXL protein, a crucial regulator of sex determination in Drosophila contains 2 RRM, and appears to be the result of such a rapid adaptation of function. In the search for genetic changes that distinguish our brains from that of our ancestors, the focus has been on the identification of non-synonymous changes in coding regions and the modification of regulatory sequences [36]. Our work suggests that the very conserved RRM-containing proteins may have contributed to human brain evolution, especially when considering the fundamental importance of the regulation of RNA metabolism in neurons, where alternative splicing [37] and localized RNA translation and degradation $[38,39]$ take place with impacts on cortex development, neuronal regeneration and plasticity.

\section{Conclusion}

The elav gene family encodes proteins with three RNA Recognition Motifs (RRM) acting as neuronal post-transcriptional regulators in all metazoans. Since they show remarkable sequence conservation, the documented diversity of their molecular roles is unexpected. We report the occurence of elav-like gene duplications and deletions in metazoans, and show that the vital elav gene of Drosophila is newly emerged, specific to dipterans and of retrotransposed origin, challenging its status of prototype for the family. These findings, together with the plasticity of the interactions between RRM and RNA, suggests that the elav-like proteins may have played an important role in the evolution of the gene functions crucial in brain evolution.

\section{Methods \\ cDNA sequences used for the analysis of coding sequence organization in the elav gene family of Drosophila melanogaster}

We used the transcripts data from FlyBase [18] to assess the relationship between RNA and protein coding regions. Multiple RNA isoforms from one gene were taken into account if they were a source of polypeptide diversity. For instance, seven alternative RNA forms have been reported for $r b p 9$, which are predicted to encode six distinct polypeptides. Only one level of variation was relevant to the present analysis, that is the alternative inclusion of a mini-exon that causes the addition of 15 nucleotides (five amino acids), hence the choice of using the rbp9-A and the rbp9-D RNA forms, that differ by the presence/absence of the mini exon. In the case of both fne and elav, several transcripts have been reported but they encode a single polypeptide.

\section{Identification of elav orthologs in completely sequenced genomes and prediction of ELAV-like protein sequences}

We used protein sequences from the data bases deduced from cDNA analysis whenever possible, with NCBI accession numbers as follows: in humans BAD92531 (HuB, 367 amino acids), AAH30692/Q12926-2 (HuB, 346 aa), AAA58677 (HuC, 359 AA), AAH14144/Q14576 (HuC, 367 AA), AAH36071/Q8IYD4 (HuD, 366 aa), AAK57541/ AAK57541 (HuD, 380 aa), AAH03376/Q15717 (HuR, 326 aa), in D. melanogaster AAA28506 (ELAV, 483 aa), AAF43091 (FNE, 356 aa), AAF51179 (RBP9 isoform A, $647 \mathrm{aa}$ ) and AAN10401 (RBP9 isoform D, $642 \mathrm{aa}$ ), in Caenorhabditis elegans NP_496057 (EXC-7, 456 aa). UniProtKB/Swiss-Prot Accession numbers are also provided for further details on the proteins: Q12926 (HuB), Q14576 (HuC), Q8IYD4 (HuD), Q15717 (HuR), P16914 (ELAV,), Q9VYI0 (FNE), Q9VQJ0 (RBP9) and Q20084 (EXC-7).

When no cDNA sequences were available, we performed searches of the entire genomes using the tblastn program [40] to identify orthologs of ELAV-related genes. We analyzed the genomic regions encoding these orthologs by performing a three frame translation of the genomic sequences, and using the gene prediction program genescan [41] as well as a splice site prediction program [42]. The predicted protein coding sequences were the result of integration and manual review of these data.

Using the procedures detailed above to identify elav orthologs, we reviewed predicted protein sequences that have been proposed for Apis mellifora, Aedes aegypti and Anopheles gambiae [19]. Some of our conclusions were consistent with the automated predictions of genome projects (A. mellifora, XP_394166, 343 aa), but we edited sequences of $A$. aegypti, and A. gambiae ELAV orthologs. 
The decision of editing was based upon the identification of manifest errors in the automated predictions, such as the prediction of a four base pair intron 5'-CCCT-3', missing the consensus GT-AG sequences typically flanking introns for the Ag-3 predicted transcript (XM_309157). For those two species, as well as for those where no prediction had yet been proposed, we relied upon the above procedure to identify and propose predicted sequences of ELAV orthologs. They respectively derive from genomic sequences CH477489 (Ae-1), CH477672 (Ae-2), CH477401(Ae-3) in A. aegypti, from CM000357 (Ag-1), CM000360 (Ag-2), CM000359 (Ag-3) in A. Gambiae, DS231997 (Cp-1), DS232556 (Cp-2), DS231816 (Cp-3) in Culex pipiens, CM000276 in Tribolium castaneum, DS265619 in Nasonia vitripennis, AADK01020611 (Bm1), CH391062 (Bm-2) in Bombyx mori and DS235033 in Pediculus humanus corporis.

In our analysis we used only the approximately 325 amino acids region of the proteins including the three RRM and a hinge region that links RRM2 and RRM3, because the N-terminus, when present, is not conserved. The sequences used are listed in Additional file 1.

\section{Identification of arginase genes in completely sequenced} genomes and prediction of arginase protein sequences Arginase sequences have been deduced from cDNA sequences for several species: human (ARG1: P05089, Arg2: P78540), D. melanogaster (Q9NHA5), C. elegans (Q22659). For the other species, we used the procedure described above to propose arginase sequences. The protein sequences derive from genomic sequences CH477248 in A. aegypti, from CM000359 in A. gambiae, DS232533 in C. pipiens, CM000280 in T. castaneum, DS265617 in N. vitripennis, CH389642 in B. mori and DS235286 in P. humanus corporis. We were not able to predict a complete $P$. humanus corporis arginase sequence, because of the lower level of conservation. See Additional file 2 for the arginase sequences.

\section{Protein sequence alignments and percentages of identity} Alignments were performed with the ClustalW program using default parameters [43]. In the case of arginases, we focused on the region homologous to that including intron 3 in D. melanogaster. The values for percentages of identity were extracted from the ClustalW score tables.

\section{Phylogenetic analysis}

We used the CLC combined workbench (CLC bio A/S) version 3.6.2 to align the 27 protein sequences with an unweighted pair group method using arithmetic averages (UPGMA) and to evaluate the reliability of the inferred tree with a bootstrap analysis (500 replicates).

\section{Authors' contributions}

The author takes full responsability for the work. She asked the question, devised the approach, performed it, analyzed the results and wrote the manuscript.

\section{Additional material}

\section{Additional file 1}

Fasta sequences of the three RRMs and the hinge regions of ELAV-like proteins. 27 Fasta sequences.

Click here for file

[http://www.biomedcentral.com/content/supplementary/1471-

2164-9-392-S1.pdf]

\section{Additional file 2}

Fasta sequences of the arginases. 12 Fasta sequences. Click here for file

[http://www.biomedcentral.com/content/supplementary/1471-

2164-9-392-S2.pdf]

\section{Additional file 3}

Protein sequence comparison among 12 arginases from 11 metazoans. Arginase sequences alignment with legend.

Click here for file

[http://www.biomedcentral.com/content/supplementary/14712164-9-392-S3.pdf]

\section{Acknowledgements}

We thank L. Rabinow, S. Mazan and P. Capy for critical reading of the manuscript. This work was supported by funding from the Centre National de la Recherche Scientifique and the University of Paris XI.

\section{References}

I. Yao KM, Samson ML, Reeves R, White K: Gene elav of Drosophila melanogaster: a prototype for neuronal-specific RNA binding protein gene family that is conserved in flies and humans. J Neurobiol 1993, 24:723-739.

2. Pascale $A$, Amadio $M$, Quattrone $A$ : Defining a neuron: neuronal ELAV proteins. Cell Mol Life Sci 2008, 65: $128-140$.

3. Keene JD: Why is Hu where? Shuttling of early-response-gene messenger RNA subsets. Proc Natl Acad USA 1999, 96:5-7.

4. Lunde BM, Moore C, Varani G: RNA-binding proteins: modular design for efficient function. Nat Rev Mol Cell Biol 2007, 8:479-490.

5. Maris C, Dominguez C, Allain FH: The RNA recognition motif, a plastic RNA-binding platform to regulate post-transcriptional gene expression. FEBS J 2005, 272:2।I8-2।3I.

6. Kim-Ha J, Kim J, Kim Y-J: Requirement of RBP9, a Drosophila Hu homolog, for regulation of cystocyte differentiation and oocyte determination during oogenesis. Mol Cell Biol 1999, 19:2505-25|4.

7. Jeong K, Kim-Ha J: Precocious expression of Drosophila Rbp9 inhibits ovarian germ cell proliferation. Mol Cells 2004, 18:230-236.

8. Samson M-L, Chalvet $F$ : found in neurons, a third member of the Drosophila elav gene family, encodes a neuronal protein and interacts with elav. Mech Dev 2003, I 20:373-383.

9. Samson M-L: Shared RNA-binding sites for interacting members of the Drosophila ELAV family of neuronal proteins. Nucleic Acids Res 2005, 33:6372-6383.

10. Good P: A conserved family of elav-like genes in vertebrates. Proc Nat Acad Sci USA 1995, 92:4557-456I.

II. Brennan CM, Steitz JA: HuR and mRNA stability. Cell Mol Life Sci 200I, 58:266-277. 
12. Kullmann M, Göpfert U, Siewe B, Hengst L: ELAV/Hu proteins inhibit p27 translation via an IRES element in the p27 5'UTR. Genes Dev 2002, I 6:3087-3099.

13. Peng SS-Y, Chen C-YA, Xu N, Shyu A-B: RNA stabilization by the AU-rich element binding protein, HuR, an ELAV protein. EMBO J 1998, I 7:346 I-3470.

14. Fan XC, Steitz JA: Overexpression of HuR, a nuclear-cytoplasmic shuttling protein, increases the in vivo stability of AREcontaining mRNAs. EMBO J 1998, I 5:3448-3460.

15. Soller M, White K: ELAV inhibits 3'-end processing to promote neural splicing of ewg pre-mRNA. Genes Dev 2003, I 7:2526-2538.

16. Zhu H, Hasman R, Barron VA, Luo G, Lou H: A nuclear function of Hu proteins as neuron-specific alternative RNA processing regulators. Mol Biol Cell 2006, I 7:5 I05-5 I I4.

17. Zhu $\mathrm{H}$, Zhou $\mathrm{H}$, Hasman RA, Lou $\mathrm{H}$ : Hu proteins regulate polyadenylation by blocking sites containing U-rich sequences. J Biol Chem 2007, 282:2203-2210.

18. Flybase, A Database of Drosophila Genes \& Genomes [http:/ /flybase.org/]

19. VectorBase, An NIAID Bioinformatics Resource Center for Invertebrate Vectors of Human Pathogens [http://www.vec torbase.org/index.php]

20. Xia Q, Zhou Z, Lu C, Cheng D, Dai F, Li B, Zhao P, Zha X, Cheng T, Chai C, Pan G, Xu J, Liu C, Lin Y, Qian J, Hou Y, Wu Z, Li G, Pan M, Li C, Shen Y, Lan X, Yuan L, Li T, Xu H, Yang G, Wan Y, Zhu Y, Yu M, Shen W, Wu D, Xiang Z, Yu J, Wang J, Li R, Shi J, Li H, Li G, Su J, Wang X, Li G, Zhang Z, Wu Q, Li J, Zhang Q, Wei N, Xu J, Sun H, Dong L, Liu D, Zhao S, Zhao X, Meng Q, Lan F, Huang X, Li Y, Fang L, Li C, Li D, Sun Y, Zhang Z, Yang Z, Huang Y, Xi Y, Qi Q, He D, Huang $\mathrm{H}$, Zhang $X$, Wang Z, Li W, Cao Y, Yu Y, Yu H, Li J, Ye J, Chen H, Zhou Y, Liu B, Wang J, Ye J, Ji H, Li S, Ni P, Zhang J, Zhang Y, Zheng H, Mao B, Wang W, Ye C, Li S, Wang J, Wong GK, Yang H, Biology Analysis Group: A Draft Sequence for the Genome of the Domesticated Silkworm (Bombyx mori). Science 2004, 306:1937-0940.

21. Mita K, Kasahara M, Sasaki S, Nagayasu Y, Yamada T, Kanamori H, Namiki N, Kitagawa M, Yamashita H, Yasukochi Y, Kadono-Okuda K, Yamamoto K, Ajimura M, Ravikumar G, Shimomura M, Nagamura Y, Shin-I T, Abe H, Shimada T, Morishita S, Sasaki T: The genome sequence of silkworm, Bombyx mori. DNA Res 2004, 29:27-35.

22. National Human Genome Research Institute, Status Approved Sequencing Targets [http://www.genome.gov/ $10002154]$

23. Wang $X$, Tanaka Hall TM: Structural basis for recognition of AU-rich element RNA by the HuD protein. Nat Struct Biol 200I, 8:14I-I45.

24. Samson M-L: Drosophila arginase is produced from a nonvital gene that contains the elav locus within its third intron. J Biol Chem 2000, 275:3 II07-3III4.

25. Drosophila 12 Genomes Consortium, Clark AG, Eisen MB, Smith DR, Bergman CM, Oliver B, Markow TA, Kaufman TC, Kellis M, Gelbart W, lyer VN, Pollard DA, Sackton TB, Larracuente AM, Singh ND, Abad JP, Abt DN, Adryan B, Aguade M, Akashi H, Anderson WW, Aquadro CF, Ardell DH, Arguello R, Artieri CG, Barbash DA, Barker D, Barsanti P, Batterham P, Batzoglou S, Begun D, Bhutkar A, Blanco E, Bosak SA, Bradley RK, Brand AD, Brent MR, Brooks AN, Brown RH, Butlin RK, Caggese C, Calvi BR, Bernardo de Carvalho A, Caspi A, Castrezana S, Celniker SE, Chang JL, Chapple C, Chatterji S, Chinwalla A, Civetta A, Clifton SW, Comeron JM, Costello JC, Coyne JA, Daub J, David RG, Delcher AL, Delehaunty K, Do CB, Ebling H, Edwards K, Eickbush T, Evans JD, Filipski A, Findeiss S, Freyhult E, Fulton L, Fulton R, Garcia AC, Gardiner A, Garfield DA, Garvin BE, Gibson G, Gilbert D, Gnerre S, Godfrey J, Good R, Gotea V, Gravely B, Greenberg AJ, Griffiths-Jones S, Gross S, Guigo R, Gustafson EA, Haerty W, Hahn MW, Halligan DL, Halpern AL, Halter GM, Han MV, Heger A, Hillier L, Hinrichs AS, Holmes I, Hoskins RA, Hubisz MJ, Hultmark D, Huntley MA, Jaffe DB, Jagadeeshan S, Jeck WR, Johnson J, Jones CD, Jordan WC, Karpen GH, Kataoka E, Keightley PD, Kheradpour P, Kirkness EF, Koerich LB, Kristiansen K, Kudrna D, Kulathinal RJ, Kumar S, Kwok R, Lander E, Langley CH, Lapoint R, Lazzaro BP, Lee SJ, Levesque L, Li R, Lin CF, Lin MF, Lindblad-Toh K, Llopart A, Long M, Low L, Lozovsky E, Lu J, Luo M, Machado CA, Makalowski W, Marzo M, Matsuda M, Matzkin L, McAllister B, McBride CS, McKernan B, McKernan K, Mendez-Lago M, Minx P, Mollenhauer MU, Montooth K, Mount SM, Mu X, Myers E, Negre B, New- feld S, Nielsen R, Noor MA, O'Grady P, Pachter L, Papaceit M, Parisi MJ, Parisi M, Parts L, Pedersen JS, Pesole G, Phillippy AM, Ponting CP, Pop M, Porcelli D, Powell JR, Prohaska S, Pruitt K, Puig M, Quesneville $H$, Ram KR, Rand D, Rasmussen MD, Reed LK, Reenan R, Reily A, Remington KA, Rieger TT, Ritchie MG, Robin C, Rogers YH, Rohde C, Rozas J, Rubenfield MJ, Ruiz A, Russo S, Salzberg SL, Sanchez-Gracia A, Saranga DJ, Sato H, Schaeffer SW, Schatz MC, Schlenke T, Schwartz R, Segarra C, Singh RS, Sirot L, Sirota M, Sisneros NB, Smith CD, Smith TF, Spieth J, Stage DE, Stark A, Stephan W, Strausberg RL, Strempel S, Sturgill D, Sutton G, Sutton GG, Tao W, Teichmann S, Tobari YN, Tomimura Y, Tsolas JM, Valente VL, Venter E, Venter JC, Vicario S, Vieira FG, Vilella AJ, Villasante A, Walenz B, Wang J, Wasserman M, Watts T, Wilson D, Wilson RK, Wing RA, Wolfner MF, Wong A, Wong GK, Wu CI, Wu G, Yamamoto D, Yang HP, Yang SP, Yorke JA, Yoshida K, Zdobnov E, Zhang P, Zhang Y, Zimin AV, Baldwin J, Abdouelleil A, Abdulkadir J, Abebe A, Abera B, Abreu J, Acer SC, Aftuck L, Alexander A, An P, Anderson E, Anderson S, Arachi H, Azer M, Bachantsang P, Barry A, Bayul T, Berlin A, Bessette D, Bloom T, Blye J, Boguslavskiy L, Bonnet C, Boukhgalter B, Bourzgui I, Brown A, Cahill P, Channer S, Cheshatsang Y, Chuda L, Citroen M, Collymore A, Cooke P, Costello M, D'Aco K, Daza R, De Haan G, DeGray S, DeMaso C, Dhargay N, Dooley K, Dooley E, Doricent M, Dorje P, Dorjee K, Dupes A, Elong R, Falk J, Farina A, Faro S, Ferguson D, Fisher S, Foley CD, Franke A, Friedrich D, Gadbois L, Gearin G, Gearin CR, Giannoukos G, Goode T, Graham J, Grandbois E, Grewal S, Gyaltsen K, Hafez N, Hagos B, Hall J, Henson C, Hollinger A, Honan T, Huard MD, Hughes L, Hurhula B, Husby ME, Kamat A, Kanga B, Kashin S, Khazanovich D, Kisner P, Lance K, Lara M, Lee W, Lennon N, Letendre F, LeVine R, Lipovsky A, Liu X, Liu J, Liu S, Lokyitsang T, Lokyitsang Y, Lubonja R, Lui A, MacDonald P, Magnisalis V, Maru K, Matthews C, McCusker W, McDonough S, Mehta T, Meldrim J, Meneus L, Mihai O, Mihalev A, Mihova T, Mittelman R, Mlenga V, Montmayeur A, Mulrain L, Navidi A, Naylor J, Negash T, Nguyen T, Nguyen N, Nicol R, Norbu C, Norbu N, Novod N, O'Neill B, Osman S, Markiewicz E, Oyono OL, Patti C, Phunkhang P, Pierre F, Priest M, Raghuraman S, Rege F, Reyes R, Rise C, Rogov P, Ross K, Ryan E, Settipalli S, Shea T, Sherpa N, Shi L, Shih D, Sparrow T, Spaulding J, Stalker J, Stange-Thomann N, Stavropoulos S, Stone C, Strader C, Tesfaye S, Thomson T, Thoulutsang Y, Thoulutsang D, Topham K, Topping I, Tsamla T, Vassiliev H, Vo A, Wangchuk T, Wangdi T, Weiand M, Wilkinson J, Wilson A, Yadav S, Young G, Yu Q, Zembek L, Zhong D, Zimmer A, Zwirko Z, Jaffe DB, Alvarez P, Brockman W, Butler J, Chin C, Gnerre S, Grabherr M, Kleber M, Mauceli E, MacCallum I: Evolution of genes and genomes on the Drosophila phylogeny. Nature 2007, 450:203-2I8.

26. Bhutkar A, Russo SM, Smith TF, Gelbart WM: Genome-scale analysis of positionally relocated genes. Genome Res 2007, I7: 1880-1887.

27. Hillier LW, Fulton RS, Fulton LA, Graves TA, Pepin KH: The DNA sequence of human chromosome 7. Nature 2003, 424: I57-I64.

28. Neufeld TP, Carthew RW, Rubin GM: Evolution of gene position: chromosomal arrangement and sequence comparison of the Drosophila melanogaster and Drosophila virilis sina and Rh4 genes. Proc Natl Acad Sci USA 1991, 88:10203-10207.

29. Akamatsu W, Fujihara H, Mitsuhashi T, Yano M, Shibata S, Hayakawa Y, Okano HJ, Sakakibara S, Takano H, Takano T, Takahashi T, Noda $\mathrm{T}$, Okano $\mathrm{H}$ : The RNA-binding protein HuD regulates neuronal cell identity and maturation. Proc Natl Acad Sci USA 2005, 102:4625-4630.

30. Loria PM, Duke A, Rand JB, Hobert O: Two neuronal, nuclearlocalized RNA binding proteins involved in synaptic transmission. Curr Biol 2003, 13:1317-1323.

31. Traut W, Niimi T, Ikeo K, Sahara K: Phylogeny of the sex-determining gene Sex-lethal in insects. Genome 2006, 49:254-262.

32. Okano HJ, Darnell RB: A hierarchy of Hu RNA binding proteins in developing and adult neurons. J Neurosci 1997, I 7:3024-3037.

33. Wang W, Caldwell MC, Lin S, Furneaux H, Gorospe M: HuR regulates cyclin A and cyclin B I mRNA stability during cell proliferation. EMBO J 2000, 1 9:2340-2350.

34. Quattrone A, Pascale A, Nogues X, Zhao W, Gusev P, Pacini A, Alkon $D:$ Posttranscriptional regulation of gene expression in learning by the neuronal ELAV-like mRNA-stabilizing proteins. Proc Natl Acad Sci USA 200 I, 98: I I668-I I673.

35. Lisbin MJ, M G, YM Y, K W: Function of RRM domains of Drosophila melanogaster ELAV: Rnp I mutations and rrm domain 
replacements with ELAV family proteins and SXL. Genetics 2000, 155:1789-1798.

36. Sikela JM: The jewels of our genome: the search for the genomic changes underlying the evolutionarily unique capacities of the human brain. PLoS Genet 2006, 2:e80.

37. Li Q, JA L, Black $D L$ : Neuronal regulation of alternative premRNA splicing. Nat Rev Neurosci 2007, 8:819-83I.

38. Lin AC, Holt CE: Local translation and directional steering in axons. EMBO / 2007, 26:3729-3736.

39. Bramham CR, Wells DG: Dendritic mRNA: transport, translation and function. Nat Rev Neurosci 2007, 8:776-789.

40. Flybase, blast [http://flybase.org/]

41. The New GENSCAN Web Server at MIT [http:// genes.mit.edu/GENSCAN.html]

42. Berkeley Drosophila Genome Project, Splice Site Prediction by Neural Network [http://www.fruitfly.org/seq tools/ splice.html]

43. EMBL-EBI, ClustalW2 [http://www.ebi.ac.uk/Tools/clustalw2/ index.html]

Publish with Bio Med Central and every scientist can read your work free of charge

"BioMed Central will be the most significant development for disseminating the results of biomedical research in our lifetime. "

Sir Paul Nurse, Cancer Research UK

Your research papers will be:

- available free of charge to the entire biomedical community

- peer reviewed and published immediately upon acceptance

- cited in PubMed and archived on PubMed Central

- yours - you keep the copyright

Submit your manuscript here:

http://www.biomedcentral.com/info/publishing_adv.asp
BioMedcentral 